\title{
Pulmonary gas exchange during exercise in young asthmatic patients ${ }^{1}$
}

\author{
KHALIL A FEISAL AND F J D FULEIHAN \\ From the Department of Internal Medicine, American University School of Medicine, Beirut, Lebanon
}

ABSTRACT Pulmonary function was examined in 19 young asthmatic patients at rest and during two levels of exercise. Findings at rest included decreased flow rates, increased residual volume, normal minute $\left(\dot{\mathrm{V}}_{\mathrm{E}}\right)$ and alveolar $\left(\dot{\mathrm{V}}_{\mathrm{A}}\right)$ ventilation, increased ratio of physiological dead space to tidal volume (VD/VT), increased alveolar-arterial oxygen tension difference $\left(\mathrm{A}-\mathrm{a} \mathrm{Po}_{2}\right)$, and mild arterial hypoxaemia and desaturation. On exercise there was a normal increase in $\dot{V}_{\mathbf{E}}$ and $\dot{\mathrm{V}}_{\mathbf{A}}$, the VD/VT and the $\mathrm{A}-\mathrm{a} \mathrm{Po}_{2}$ decreased towards normal, and arterial oxygen tension improved, approaching normal levels. Significant acidosis did not develop.

Pulmonary function patterns in patients with asthma of varying severity have been adequately described (Bates et al, 1971). Exercise-induced bronchospasm, in particular, has received much attention (McNeill et al, 1966; Rebuck and Read, 1968; Fisher et al, 1970; Vassallo et al, 1972; Haynes et al, 1976). Studies of the physical fitness of asthmatic children and the effect of controlled exercise on their physical and social rehabilitation have been reported (Millman et al, 1965; Sly et al, 1972), but little information is available on the effects of exercise on ventilation and gas exchange (Beaudry et al, 1967; Vavra et al, 1969). Thus we were prompted to study ventilation and gas exchange alterations after graded exercise in a group of young asthmatic patients.

\section{Patients and methods}

Nineteen (13 male, six female) asthmatic patients were studied. Their ages ranged from 13 to 30 (mean age $19 \cdot 3$ years). All had a family history of asthma or hay fever, and all suffered from moderately severe spasmodic asthma, the average duration of which was 9.1 years (range 1-19). All took bronchodilators, and three took corticosteroids regularly. Informed consent was obtained from all.

All patients were studied in the morning. They had been instructed not to take their medications, except for corticosteroids, on the morning of the study.

Forced vital capacity (FVC) and flow rates were determined using a 9-litre Collins spirometer. The best of three tracings within $10 \%$ of one another and

${ }^{1}$ Supported in part by a research grant from Fisons Pharmaceutical Company, Loughborough, Leicestershire, UK. the prediction formulae of Goldman and Becklake (1959) were used. From these data the forced expiratory volume in one second $\left(\mathrm{FEV}_{1}\right)$ and the forced expiratory flow over the middle $50 \%$ of the vital capacity $\left(\mathrm{FEF}_{25-75}\right)$ were calculated. Total lung capacity (TLC) was measured in duplicate using a closed-circuit helium dilution method (Bates and Christie, 1950). The average of two determinations that agreed to within $3 \%$ was used. Residual volume was obtained by subtracting the best vital capacity from the average TLC. Single breath diffusing capacity for carbon monoxide was determined by the method of Ogilvie et al (1957).

An indwelling Riley needle was placed in the brachial artery using $2 \%$ lidocaine anaesthesia. The subject then rested for 20-30 minutes. After several washouts, expired gas was collected for three minutes in a Tissot spirometer and simultaneously an arterial blood sample was obtained in the sitting position. The subject then exercised on a cycle ergometer (SiemensElema, Solna 1, Sweden); male subjects exercised at 250 and 500 kilopond-metres a minute $(\mathrm{Kpm})$ and female subjects at 200 and $400 \mathrm{Kpm}$ for five minutes at each level. During the fifth minute expired gas was collected and a simultaneous arterial blood sample over several breaths was obtained. Arterial blood gas was analysed for oxygen $\left(\mathrm{PO}_{2}\right)$ and carbon dioxide $\left(\mathrm{PCO}_{2}\right)$ tensions and for $\mathrm{pH}$ using electrodes manufactured by Radiometer, Copenhagen. Expired gas was analysed using a micro-Schölander apparatus.

From these data minute $\left(\dot{\mathrm{V}}_{\mathrm{E}}\right)$ and alveolar $\left(\dot{\mathrm{V}}_{\mathbf{A}}\right)$ ventilation, oxygen consumption $\left(\mathrm{V}_{2}\right), \mathrm{CO}_{2}$ production $\left(\dot{\mathrm{V}} \mathrm{CO}_{2}\right)$, and respiratory exchange ratio $(\mathrm{R})$ were calculated using standard formulae (Comroe $e t$ 
al, 1962). Lung volumes and minute and alveolar ventilation were corrected to BTPS. Oxygen consumption and $\mathrm{CO}_{2}$ production were corrected to STPD. Alveolar oxygen tension $\left(\mathrm{PAO}_{2}\right)$ was obtained from the alveolar air equation, and the alveolararterial $\mathrm{Po}_{2}$ gradient $\left(\mathrm{A}-\mathrm{a} \mathrm{PO}_{2}\right)$ was determined. Physiological dead space (VD) was calculated using the Bohr equation, assuming arterial $\mathrm{PCO}_{2}$ to be equal to alveolar $\mathrm{PCO}_{2}$.

The data were analysed for differences between exercise levels using $t$ tests (Snedecor and Cochran, 1967).

\section{Results}

Table 1 shows the resting lung volumes, flow rates, and diffusing capacity in the subjects. The vital capacity was within normal limits. The flow rates were moderately decreased, and there was hyperinflation. The diffusing capacity was normal.

Table 1 Resting pulmonary function in asthmatics (means $\pm S D$ )

\begin{tabular}{|c|c|}
\hline \multicolumn{2}{|l|}{ Test } \\
\hline $\begin{array}{l}\text { Forced vital capacity (1) } \\
\% \text { predicted } \\
\text { Forced expiratory volume in } 1 \mathrm{~s}(1) \\
\text { FEV } / \text { FVC } \% \\
\text { Forced expiratory flow, } 25-75 \% \text { vital capacity }\left(\mathrm{ls}^{-1}\right) \\
\text { Total lung capacity (l) } \\
\% \text { predicted } \\
\text { Residual volume (l) } \\
\text { RV/TLC \% } \\
\text { Transfer factor per } \mathbf{M}^{2} \mathrm{BSA}\left(\mathrm{ml} \mathrm{min}{ }^{-1} \mathrm{mmHg}^{-1} \mathrm{M}^{-2}\right)\end{array}$ & $\begin{array}{l}3 \cdot 85 \pm 0 \cdot 98 \\
103 \cdot 5 \pm 18 \cdot 3 \\
2 \cdot 32 \pm 0 \cdot 87 \\
59 \cdot 2 \pm 12 \cdot 4 \\
1 \cdot 54 \pm 1 \cdot 0 \\
5 \cdot 96 \pm 1 \cdot 32 \\
127 \cdot 7 \pm 13 \cdot 5 \\
2 \cdot 12 \pm 0 \cdot 96 \\
35 \cdot 5 \pm 12 \cdot 0 \\
21 \cdot 1 \pm 3 \cdot 7\end{array}$ \\
\hline
\end{tabular}

The results of ventilation, gas exchange, and arterial blood gas determinations at rest and on exercise are shown in table 2. The minute and alveolar ventilation and the $\dot{\mathrm{V}}_{2}$ and $\dot{\mathrm{VCO}}_{2}$ were comparable to predicted normal values (Jones et al, 1975). There was mild arterial hypoxaemia at rest which improved significantly $(P<0.01)$ with mild exercise to nearly normal levels. The $\mathrm{PAO}_{2}$ on the other hand was normal at rest and on exercise. Thus the A-a $\mathrm{Po}_{2}$, abnormally wide at rest, decreased on exercise but remained significantly abnormal (Hesser and Matell, 1965). The $\mathrm{PCO}_{2}$ was at the lower limit of normal and did not change with exercise. The $\mathrm{pH}$ was normal at rest, decreased significantly with exercise, but remained within physiologically normal limits. The ratio of physiological dead space to tidal volume (VD/VT) was increased at rest but decreased to normal levels during exercise (Jones et al, 1966).

In an attempt to determine whether the severity of airways obstruction at rest influenced the response to exercise, we compared the exercise values of the patients arbitrarily divided into a group of eight with
Table 2 Ventilation and gas exchange values at rest and two levels of exercise $\left(E_{1}\right.$ and $\left.E_{2}\right)$ in asthmatic patients. Exercise 1: 200-250 Kpm; Exercise 2: 400-500 K pm. Means \pm Standard Deviation

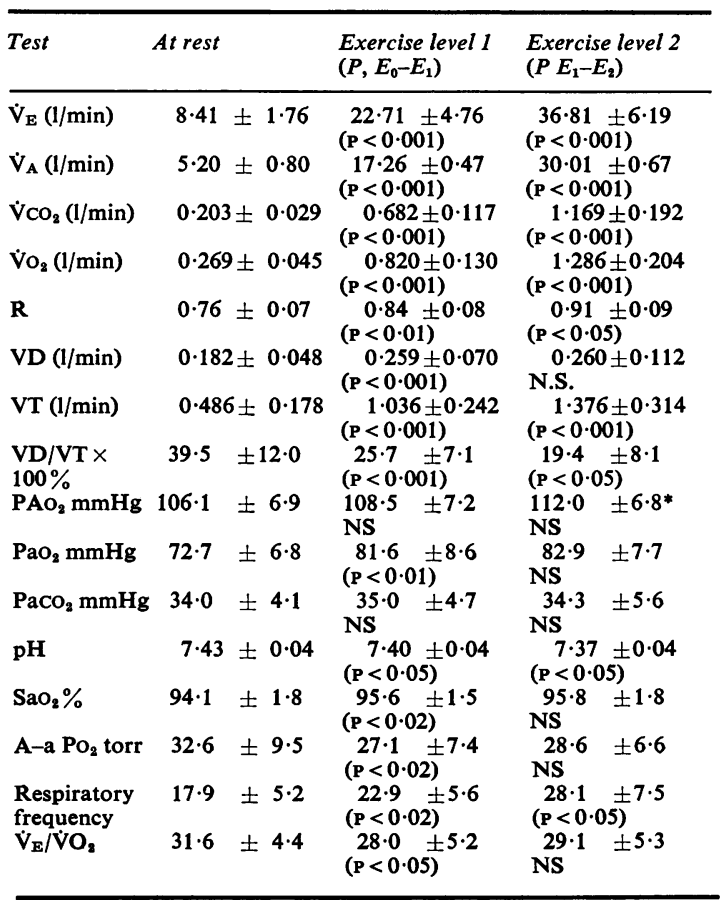

*Difference in alveolar $\mathrm{Po}_{2}$ between rest and the second level of exercise is significant at the $2 \%$ level.

Conversion of $\mathrm{mmHg}$ to SI units: $1 \mathrm{kPa}=7 \cdot 5$ torr.

Symbols as in text.

an $\mathrm{FEV}_{1}$ less than 21 and a group of 11 with an $\mathrm{FEV}_{1}$ greater than 21 . The patients with the lower FEV 1 had a greater respiratory frequency, a lower tidal volume, and a wider $\mathrm{A}-\mathrm{a} \mathrm{Po}_{2}$ at the higher exercise level (table 3). The patients with a lower $\mathrm{FEV}_{1}$ also had a lower $\mathrm{Po}_{2}$ at rest and at both exercise levels.

\section{Discussion}

Most previous studies of asthmatic patients during o exercise have dealt with the effect of exercise on flow $D$ rates and lung compliance. Itkin and Nacman (1966) $\omega$ studied 39 young asthmatics and showed that brief ${ }^{\circ}$ (1-2 min) exercise increased the $F^{2} V_{1}$ whereas 0

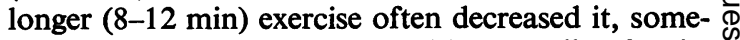
times during the exercise period but usually after its ? completion. Jones et al (1963) also showed that $\frac{T}{3}$ asthmatics had increased flow rates during exercise $\underset{\mathbb{D}}{\stackrel{\circ}{(}}$ with a postexercise reduction. Bevegärd et al (1976) $\cong$ showed that severe asthmatics had increased minute $\stackrel{\varnothing}{\varrho}$ ventilation during exercise; however, maximal oxygen consumption and aerobic muscle power were normal. 
Table 3 Ventilation and gas exchange data correlated with resting airways obstruction

\begin{tabular}{|c|c|c|c|c|c|c|c|}
\hline \multirow[b]{2}{*}{$\begin{array}{l}\mathrm{FEV}_{1} \\
\mathrm{No} \\
\mathrm{PaO}_{2}\end{array}$} & \multicolumn{2}{|l|}{ At rest } & \multicolumn{2}{|l|}{ Exercise level 1} & \multicolumn{3}{|l|}{ Exercise level 2} \\
\hline & $\begin{array}{l}<2 L \\
8 \\
68 \cdot 6 \pm 7 \cdot 8\end{array}$ & $\begin{array}{c}{ }_{11}^{>2 L} \\
75 \cdot 7 \pm 4 \cdot 0\end{array}$ & $\begin{array}{ll} & <2 L \\
8 & \\
77.0 \pm & 8.6 \\
: & P<0.05\end{array}$ & $\begin{array}{l}>2 \mathrm{~L} \\
11 \\
84 \cdot 9 \pm \quad 7 \cdot 3\end{array}$ & $\begin{array}{ll}<2 L & \\
8 & \\
78.6 \pm & 9.5 \\
& P \simeq 0.05\end{array}$ & $\begin{array}{c}>2 L \\
11 \\
86 \cdot 1 \pm 4\end{array}$ & $1 \cdot 3$ \\
\hline VT & $463 \pm 69$ & $503 \pm 230$ & $928 \pm 216_{\text {NS }}^{1}$ & $1114 \pm 238$ & $1189 \pm 195 \quad \mathrm{P}<0.02$ & $2^{1513} \pm 32$ & \\
\hline VD/VT & $37.9 \pm 7.8$ & $40 \cdot 7 \pm 14 \cdot 6$ & $\begin{array}{rl}29.9 & 8.6 \\
& P<0.05\end{array}$ & $22 \cdot 6 \pm \quad 3.9$ & $\begin{array}{c}20 \cdot 3 \pm \underset{\text { NS }}{8 \cdot 0} \\
\text { N }\end{array}$ & $18 \cdot 7 \pm$ & $8 \cdot 6$ \\
\hline Respiratory frequency & $17 \cdot 8 \pm 2 \cdot 4$ & $18 \cdot 0 \pm \quad 6 \cdot 7$ & $25 \cdot 3 \pm \underset{\text { NS }}{3 \cdot 6}$ & $21 \cdot 2 \pm \quad 6 \cdot 4$ & $\begin{array}{ll}32.4 \pm & 8.2 \\
& P<0.05\end{array}$ & $5^{24 \cdot 9 \pm}$ & $5 \cdot 2$ \\
\hline $\mathrm{A}-\mathrm{a} \mathrm{PO}_{2}$ & $36 \cdot 4 \pm 8 \cdot 5$ & $29 \cdot 9 \pm 9 \cdot 7$ & $\begin{array}{l}29 \cdot 4 \pm \quad \text { NS } \\
\end{array}$ & $25 \cdot 4 \pm 6 \cdot 3$ & $\begin{aligned} 32.6 \pm & \begin{array}{l}6.7 \\
P<0.05\end{array}\end{aligned}$ & $5^{25 \cdot 7 \pm}$ & $5 \cdot 1$ \\
\hline
\end{tabular}

Symbols and abbreviations as in text.

Data were analysed in the same manner for $\dot{\mathrm{V}}_{\mathrm{E}}, \mathrm{VD}, \mathrm{PCO}_{2}, \mathrm{pH}, \mathrm{Vo}_{\mathbf{z}}, \mathrm{VcO}$ and no significant correlation with degree of airways obstruction was found.

$*$ Value very slightly over $P=0.05$.

$1 \mathrm{kPa}=7 \cdot 5$ torr.

In this group the ratio of the tidal volume to the vital capacity was greater than $50 \%$; blood lactate was also increased in relation to $\mathrm{Vo}_{2}$. These authors commented on the normal circulatory and respiratory function in severe asthmatics and on their good response to exercise. Vavra et al (1969) divided 32 young asthmatics into three groups on the basis of frequency of symptoms and pulmonary function abnormalities. The subjects were then exercised on three consecutive days at progressive weight-related levels. Their results, which are presented only in graphic form, showed increased minute ventilation, increased ventilatory equivalent for oxygen $\left(\dot{\mathrm{V}}_{\mathbf{E}} / \dot{\mathrm{V}}_{2}\right)$, and pronounced lactic acidosis in the group with the severest disease. Inspection of their figures shows no change in arterial saturation with exercise; this, in view of the lowered $\mathrm{pH}$, suggests that the $\mathrm{Po}_{2}$ did in fact rise (Bohr effect). These authors concluded that ventilation did not limit oxygen transport but that a circulatory limitation to oxygen transport existed, which they attributed to poor general conditioning.

In a careful study of pulmonary response to exercise in asthma, Haynes et al (1976) showed that $\dot{V}_{2}$, $\dot{\mathrm{V}} \mathrm{CO}_{2}$, and $\dot{\mathrm{V}}_{\mathrm{E}}$ did not differ significantly from normal, but the $\dot{V}_{E}$ was achieved at a higher frequency and lower tidal volume in the asthmatics. The asthmatics had a lower end-tidal $\mathrm{PCO}_{2}$ and a higher $\dot{\mathrm{V}}_{\mathbf{E}} / \dot{\mathrm{V}}_{2}$. These patients exercised at a heavier work load than ours, and this may explain their increased $\dot{\mathrm{V}}_{\mathrm{E}} / \dot{\mathrm{V}}_{2}$. Beaudry et al (1967) studied 12 asthmatic children in remission at rest and during exercise on a cycle ergometer. They observed that the mean FEV and the physiological dead space did not change after exercise, but that the VD/VT decreased. They also showed a significant metabolic acidosis and a rise in the respiratory exchange ratio in four of their asthmatics without an accompanying rise in $\mathrm{PCO}_{2}$. These workers used arterialised capillary blood and did not report $\mathrm{Po}_{2}$ values.
In our patients the average $\mathrm{pH}$ remained within normal physiological limits on exercise, but six out of 19 had a pH below 7.35 during the higher exercise level. Similarly, although the average $\mathrm{PCO}_{2}$ was low normal at rest and did not change with exercise, four patients had a $\mathrm{PcO}_{2}$ below 30 torr $(4 \mathrm{kPa})$ during the higher exercise level, and one had a $\mathrm{PCO}_{2}$ of 45 torr $(6 \mathrm{kPa})$. Estimation of base deficit from the SigaardAndersen nomogram showed evidence of metabolic acidosis (base deficit -5) in nine of the 19 subjects. Unfortunately blood lactate levels were not determined.

Our most interesting observation is the increase in $\mathrm{Po}_{2}$ to low normal levels that occurred in the asthmatics during even mild exercise. This is in contrast to the usual relative constancy of arterial $\mathrm{Po}_{2}$ during exercise in the normal subjects and is similar to, though greater than, the increase reported by Jones (1966) in chronic bronchitis. Jones explained his findings by postulating improved ventilation in areas of the lungs that had a low ventilation/blood flow $(\dot{V} / \dot{Q})$ ratio at rest, presumably a result of opening up of narrowed small airways. This would be consistent with the improved flow rates observed during exercise in the studies quoted earlier (Irnell and Swartling, 1966; Itkin and Nacman, 1966) and may reflect the increased tidal volume and the associated increase in end-inspiratory transpulmonary pressure.

Another likely explanation for the improved $\mathbf{P o}_{2}$ stems from the observation that the apices of the lungs are better perfused during exercise (West, 1963). Since airway closure is more likely to occur at the base of the lung because of the gradient of transpulmonary pressure down the pleural surface, at any level of bronchoconstriction the small airways are more likely to be open in the apices than at the bases. Thus the increase in apical blood flow during exercise will improve (that is, decrease) the $\dot{V} / Q$ ratio in the upper zones and thus possibly decrease the proportion of 
blood going to low $\dot{V} / \dot{Q}$ areas at the bases. The effect of either or both of these possibilities would be a decrease in the $\mathrm{A}-\mathrm{a} \mathrm{Po}_{2}$, which we have observed, and which is similar to that observed by Whipp and Wasserman (1969) in normal subjects at comparable work levels.

In conclusion we have shown that a group of moderately severe young asthmatic patients tolerated moderate exercise well, with improvement in arterial oxygenation and relatively normal pulmonary gas exchange.

\section{References}

Bates, D V, and Christie, R V (1950). Intrapulmonary mixing of helium in health and in emphysema. Clinical Science, 9, 17-27.

Bates, D V, Macklem, P T, and Christie, R V (1971). Respiratory Function in Disease, 2nd edn. Saunders, Philadelphia.

Beaudry, P H, Wise, M B, and Seely, J E (1967). Respiratory gas exchange at rest and during exercise in normal and asthmatic children. Amsrican Review of Respiratory Disease, 95, 248-254.

Bevegärd, S, Eriksson, B O, Graff-Lonnevig, V, Kraepelien, S, and Saltin, B (1976). Respiratory function, cardiovascular dimensions and work capacity in boys with bronchial asthma. Acta Paediatrica Scandinavica, 65, 289-296.

Comroe, J H, Forster, R E, DuBois, A B, Briscoe, W A, and Carlsen, E (1962). The Lung: Clinical Physiology and Pulmonary Function Tests, 2nd edn. Year Book Medical Publishers, Chicago.

Fisher, H K, Holton, P, Buxton, R, and Nadel, J A (1970). Resistance to breathing during exerciseinduced asthma attacks. American Review of Respiratory Disease, 101, 885-896.

Goldman, H, and Becklake, M R (1959). Respiratory function tests: Normal values of median altitudes and the prediction of normal results. American $R e$ view of Tuberculosis, 79, 457-467.

Haynes, $\mathbf{R}$ L, Ingram, $\mathbf{R} \mathbf{H}$ jun, and McFadden, E R jun (1976). An assessment of the pulmonary response to exercise in asthma and an analysis of the factors influencing it. American Review of Respiratory Disease, 114, 739-752.

Hesser, C M, and Matell, G (1965). Effects of light and moderate exercise on $\mathrm{A}-\mathrm{aO}_{2}$ tension difference in man. Acta physiologica Scandinavica, 63, 247256.

Irnell, L, and Swartling, S (1966). Maximal expiratory flow at rest and during muscular work in patients with bronchial asthma. Scandinavian Journal of Respiratory Disease, 47, 103-113.

Itkin, I H, and Nacman, M (1966). The effect of exercise on the hospitalized asthmatic patient. Journal of Allergy, 37, 253-263.

Jones, N L (1966). Pulmonary gas exchange during exercise in patients with chronic airways obstruction. Clinical Science, 31, 39-50.

Jones, N L, Campbell, E J M, Edwards, R H T, and Robertson, D G (1975). Clinical Exercise Testing. Saunders, Philadelphia.

Jones, N L, McHardy, G J R, Naimark, A, and Campbell, E J M (1966). Physiological dead space and alveolar-arterial differences during exercise. Clinical Science, 31, 19-29.

Jones, R S, Wharton, M J, and Buston, M H (1963). The place of physical exercise and bronchodilator drugs in the assessment of the asthmatic child. Archives of Diseases in Childhood, 38, 539-545.

McNeill, R S, Nairn, J R, Millar, J S, and Ingram, C G (1966). Exercise-induced asthma. Quarterly Journal of Medicine, 35, 55-67.

Millman, M, Grundon, W G, Kasch, F, Wilkerson, B, and Headley, J (1965). Controlled exercise in asthmatic children. Annals of Allergy, 22, 220-225.

Ogilvie, C M, Forster, R E, Blakemore, W S, and Morton, J W (1957). A standardized breath-holding technique for the clinical measurement of the diffusing capacity of the lung for carbon monoxide. Journal of Clinical Investigation, 36, 1-17.

Rebuck, A S, and Read, J (1968). Exercise-induced asthma. Lancet, 2, 429-430.

Sly, R M, Harper, R T, and Rosselot, I (1972). The effect of physical conditioning upon asthmatic children. Annals of Allergy, 30, 86-94.

Snedecor, G W, and Cochran, W G (1967). Statistical Methods, 6th edn. Iowa State University Press, Ames, Iowa.

Vassallo, C L, Gee, J B L, and Domm, B M (1972). Exercise-induced asthma. American Review of Respiratory Disease, 105, 42-49.

Vavra, J, Macek, M, and Spicak, V (1969). La capacité de travail chez les enfants asthmatiques. Revue de Pédiatrie, 5, 3-7.

West, J B (1963). Distribution of gas and blood in the normal lungs. British Medical Bulletin, 19, 53-58.

Whipp, B J, and Wasserman, K (1969). Alveolar- N arterial gas tension differences during graded exercise. Journal of A pplied Physiology, 27, 361-365.

Requests for reprints to: Dr K A Feisal, Department $\sigma$ of Internal Medicine, American University School of Medicine, Beirut, Lebanon. 